\title{
ESTIMATING ICE THICKNESS IN SOUTH GEORGIA FROM SRTM ELEVATION
} DATA

\author{
A P R Cooper ${ }^{\mathrm{a}^{*}}$, J W Tate ${ }^{\mathrm{b}}$, A J Cook
}

${ }^{a}$ British Antarctic Survey, High Cross, Madingley Road, Cambridge CB3 0ET, UK - (aprc, acook)@bas.ac.uk

${ }^{\mathrm{b}}$ Dept. of Civil, Environmental and Geomatic Engineering, University College London, Gower Street, London, WC1E 6BT UK james.tate@ucl.ac.uk

KEY WORDS: South Georgia, Glaciology, ice thickness, SRTM, Climate change

\begin{abstract}
:
South Georgia is a glaciated island in the South Atlantic, which provides a primary nesting site for the albatrosses and petrels of the Southern Ocean. $60 \%$ of the island is covered by glaciers and ice fields, and the majority of the coastal glaciers are observed to be retreating. A small number of these glaciers are advancing, and others are retreating at anomalously fast rates. As the status of these glaciers is important for environmental management of South Georgia, potentially controlling the spread of invasive species into currently pristine regions, it is necessary to understand the pattern of glacier change in South Georgia. However, detailed study of the glaciology of South Georgia is hampered by lack of measurements of the thickness of the ice. Because of the logistic difficulties of operating on South Georgia, there are no conventional ice thickness measurements from drilling, radar or seismic techniques, and it is unlikely that these will be available in the near future.

This paper addresses this lack of basic information by using surface slope data to estimate the ice thickness of glaciers and ice fields in South Georgia. The surface slope data are derived using surface elevations from the Shuttle Radar Topographic Mission, which provides elevation measurements with a high relative accuracy. The estimate of ice thickness critically depends on assumptions about the conditions in the ice column and at the base of the ice mass, and areas where the estimate is clearly in error provide an insight into changed ice flow conditions or the environment at the ice/rock interface. These anomalous regions are then compared with glacier change data, providing insights into the reasons for the unusually rapid retreat or advance of certain glaciers.

The paper describes the methodology used to compute ice thickness values, with an estimate of accuracy and variability of the thickness measures under different assumptions. The paper then identifies regions with anomalous thickness measurements, and seeks to ascertain why the thickness measurement is unreliable in certain regions. Finally these anomalous areas are compared with coastal change data to suggest why certain glaciers are retreating or advancing more rapidly than the norm for South Georgia, and to make predictions concerning future glacier change.
\end{abstract}

\footnotetext{
${ }^{*}$ Corresponding Author
} 


\section{INTRODUCTION}

The island of South Georgia is located in the South Atlantic centred on $54^{\circ} \mathrm{S}, 37^{\circ} \mathrm{W}$ (Figure 1). It is isolated, and heavily glaciated, with $60 \%$ of the island being covered by glaciers or ice sheets. Its location and isolation make it the primary breeding ground for many species of marine birds, such as albatrosses, petrels and penguins.

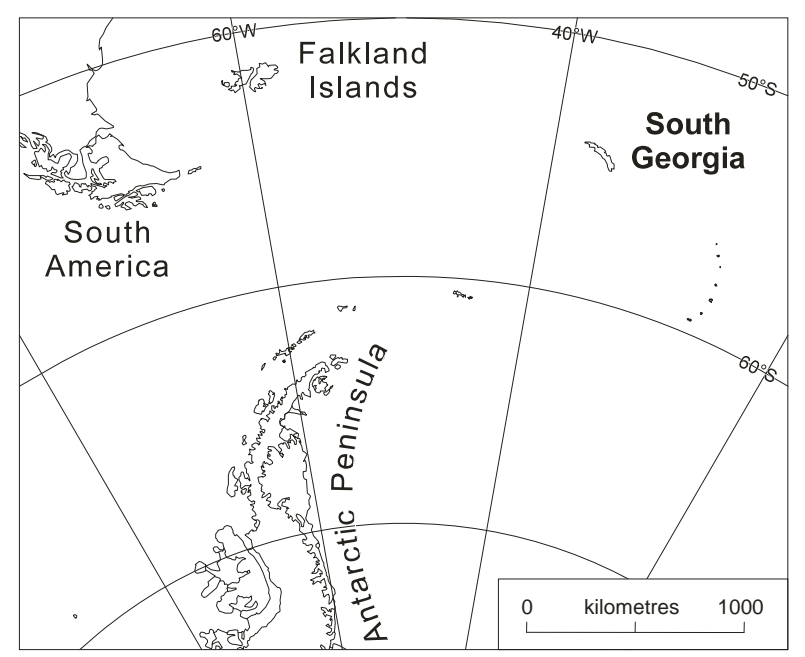

Figure 1: Location map for South Georgia

Recent studies (Cook et al., 2009) have shown that the majority of coastal glaciers on South Georgia are in retreat. A small minority are, however, advancing, and a further small number are retreating far more rapidly than the average. As Cook et al. (2009) show, these changes in glacier extent may have significant consequences on the breeding success of these iconic birds. Introduced terrestrial predators, in particular rats, are currently blocked from major breeding grounds by glacier barriers, and continuing retreat of glaciers threatens these breeding grounds. Comparison of areas occupied by rats and those not shows that most species of bird nesting in South Georgia cannot breed successfully in areas inhabited by rats.

In order to understand glacier dynamics, a crucial parameter is ice thickness. This can be measured in a variety of ways using standard techniques such as seismic sounding, icepenetrating radar or even by drilling. However, all these techniques require substantial logistic support, which is not available in South Georgia. South Georgia is only accessible by ship; there is no landing ground for fixed-wing aircraft. While an over-snow expedition could potentially carry out a survey of ice thickness, it would be limited in its areal coverage compared with airborne survey. Aircraft equipped for ice-penetrating radar surveys do not have sufficient range to perform a survey over South Georgia after flying from the nearest airfield at Port Stanley in the Falkland Islands.

Fortunately, South Georgia was covered by the Shuttle Radar Topography Mission (SRTM) during February 2000, being just north of the southern limit of $56^{\circ} \mathrm{S}$. The product used was DTED 1, 3 arc-second product ( $\sim 90 \mathrm{~m}$ post spacing). SRTM elevations have an absolute accuracy of 8 metres (90\% probability) for islands, and a relative accuracy of 6.2 metres (Farr et al., 2007). Farr et al. also state that accuracies are worst over steep slopes, and better for flat areas, such as glaciers and ice fields, though the improvement of accuracy over flatter areas is not quantified. These relatively accurate elevation data permit an estimate of ice thickness to be made from the surface slope of the glaciers (Paterson, 1981, page 86).
In places, the ice thickness estimates are clearly substantially in error, giving unrealistically high estimates. This can be linked to changes at the base of the glacier, providing an insight into conditions that are relevant to the pattern of retreat of coastal glaciers.

\section{METHOD}

\subsection{Theory}

The surface slope of a glacier in a steady state is related to the ice thickness by the following relationship:

$$
\tau=\rho \cdot g \cdot h \cdot \sin \alpha
$$

Where $\tau$ is the basal shear stress, $\rho$ is the density of ice, $g$ is the acceleration due to gravity, $\mathrm{h}$ is the ice thickness and $\alpha$ is the surface slope (Paterson, 1981, page 86).

This equation can be re-arranged to provide a relationship between ice thickness and surface slope, assuming a constant basal shear stress:

$$
\boldsymbol{h}=\frac{\tau}{\rho \cdot g \cdot \sin \tau \tau}
$$

So, assuming that the retarding forces at the base of the glacier $(\tau)$ are unvarying, it is possible to estimate ice thickness using surface slope values alone, as all other terms in the equation are constant. The value of $\tau$ varies within the range $50 \mathrm{kPa}$ to $150 \mathrm{kPa}$ depending on a variety of factors including the temperature of the ice and the nature of the substrate; a reasonable assumption for its value in the absence of other information is therefore $100 \mathrm{kPa}$.

Glaciers in South Georgia are constrained by valley walls, so additional corrections are required to account for this.

$$
\boldsymbol{h}=\frac{\tau}{\rho \cdot g \cdot \sin \alpha \cdot E}
$$

Where $\mathrm{F}$ is a correction factor that depends on $\mathrm{W}$, the ratio of the distance to the valley wall and the ice thickness on the centre-line of the glacier. GIS techniques detailed below allowed the distance to the valley wall to be computed accurately, and $\mathrm{F}$ was obtained from Table 1.

Given that much of South Georgia is covered by perennial snow or ice, determining the location of glacier margins is not trivial. A variety of techniques were tested, but the most reliable was clipping the slope data at a value of $17^{\circ}$. Methods based on image analysis using a composite Landsat ETM+ image failed due to snow cover on glaciers and heavy shadowing, but were used to eliminate areas of low slope that are not snow-covered (e.g. deglaciated areas in front of retreating glacier snouts). The second derivative of the surface (i.e. rate of change of slope) in many areas provided a good delineation of the edge of a glacier, but failed in areas where the glacier merged into snow-fields and at ice-falls. Having determined the glacier margins, the next step was to compute the glacier centrelines. This was done by computing the Euclidean distance from the glacier margins, the centreline is then the trace of the maximum distances from the glacier margins. The distance to the glacier wall is then available at every point along the glacier centre-line, and the mean ice thickness can be computed by averaging over a small region along the centre-line. These parameters are used to compute the correction factor in Equation 3 (above). 


\begin{tabular}{rrr}
\hline $\mathbf{W}$ & \multicolumn{2}{c}{$\begin{array}{l}\text { F } \\
\text { (Parabola) }\end{array}$} \\
\hline & 1 & 0.445 \\
2 & 0.646 \\
3 & 0.746 \\
& 0.806 \\
4 & 1.000 \\
\hline
\end{tabular}

Table 1: Table of corrections for a glacier with a parabolic cross-section (Paterson, 1981, p 103)

\subsection{Assumptions}

In order to estimate ice thickness using the technique described above, certain assumptions are made. These are:

1. That the glacier is flowing by plastic deformation.

2. That ice motion is primarily horizontal.

3. That the limiting basal stress is constant.

4. That the value of the limiting basal stress is $100 \mathrm{kPa}$

5. That the cross-section of the glacier is approximated by a parabola.

A further issue is that there is a likely (but nor precisely known) difference in the surface measured by the SRTM radar between ablation and accumulation areas of the glacier, caused by differences in the density of firn and glacier ice. However, this will not affect the overall results of this analysis, as the surface density of the ice changes slowly with horizontal location.

These assumptions all break down under certain circumstances, which will be discussed further below. However, assumption 4 is unavoidable; there is no way of estimating the actual limiting shear stress. $100 \mathrm{kPA}$ is a reasonable value; measured values (computed for glaciers where the ice thickness is known) vary over a range from 50 $\mathrm{kPa}$ to $150 \mathrm{kPa}$ (Paterson, 1981, page 86); values computed for the Antarctic ice sheets show lower values in certain areas where it is likely that the base of the glacier is lubricated (Drewry, 1983, Sheet 5). Assumption 5 is made for a limited range of cross-sectional shapes, and a parabola is the most realistic. However, computations of the correction factor for other cross-sectional profiles only vary by about $10 \%$ from each other; errors from breakdown of this assumption will be small compared with other sources of error.

\section{RESULTS}

The results of the estimation of ice thickness are shown in Figure 2 and summarized in Table 2. As breakdown of the assumptions detailed in Section 2.2 results in overestimates of ice thickness in almost all cases, high ice thicknesses are more likely to be incorrect than lower ice thickness estimates. Figure 3 shows an area where surface slopes are very low in the accumulation area of several glaciers; as can be seen from the $100 \mathrm{~m}$ contours of ice thickness, the apparent thickness gradient increases rapidly as the ice thickness increases, being so great when estimated ice thickness exceeds $1000 \mathrm{~m}$ that contours above $1000 \mathrm{~m}$ have been omitted. These high and rapidly changing slopes are not found in deglaciated terrain, and are unlikely to be real. Therefore, the likelihood of the estimate being correct decreases with increasing estimated ice thickness. Similarly, high ice thicknesses in the lower parts of certain glaciers, as shown in Figures 7-10, are also correlated with high thickness gradients, again suggesting that these high estimates are caused by breakdown of the assumption that the glacier is closely coupled to its bed and is moving by plastic deformation.

\section{Figure 2 Estimated Ice Thickness, with locations mentioned in the text.}

convenience; these parameters have only been computed for

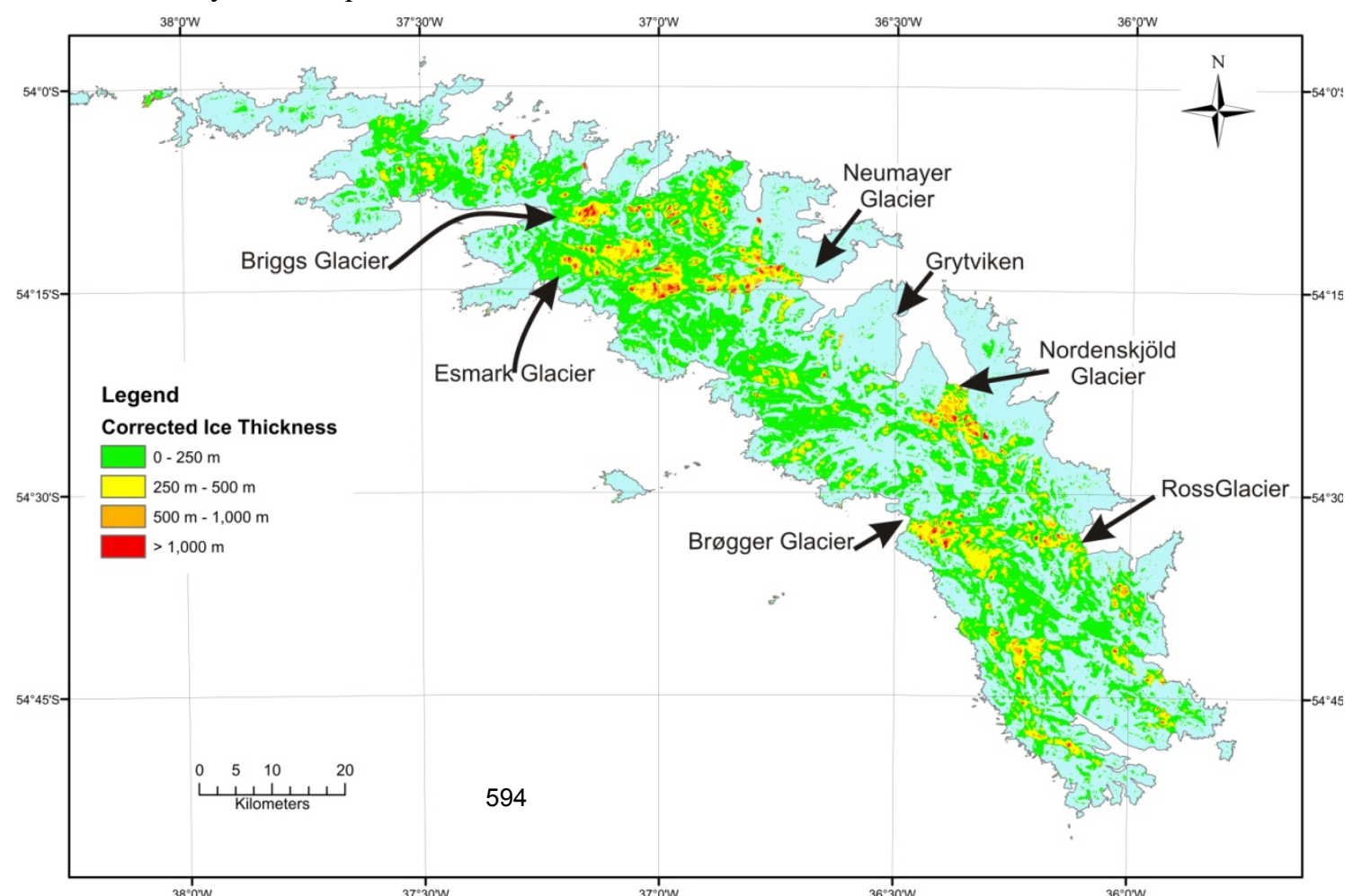




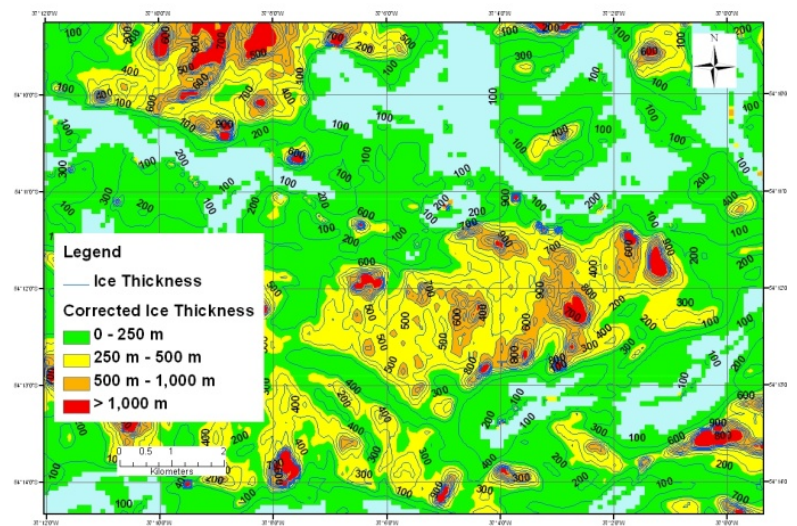

Figure 3 Ice thicknesses illustrating errors

In Figure 2, ice thicknesses have been divided into four colour bands corresponding to the likelihood of the results being correct. Inspection of ice thickness gradients suggests that ice thickness estimates between 0 and $250 \mathrm{~m}$ are likely to be an accurate reflection of the actual ice thickness (green on Figure 2), estimates between $250 \mathrm{~m}$ and $500 \mathrm{~m}$ (yellow on Figure 2) are probably subject to errors in some locations; estimates between $500 \mathrm{~m}$ and $1000 \mathrm{~m}$ (orange on Figure 2) are very likely to be incorrect, and estimates exceeding 1000 $\mathrm{m}$ (red on Figure 2) are highly unlikely to be correct.

\begin{tabular}{rrrr}
\hline $\begin{array}{l}\text { Thickness } \\
\text { Band }\end{array}$ & $\begin{array}{l}\text { Number } \\
\text { of pixels }\end{array}$ & $\begin{array}{l}\text { Area } \\
\left.\mathbf{( k m}^{2}\right)\end{array}$ & $\begin{array}{l}\text { \% of ice } \\
\text { area }\end{array}$ \\
\hline $0-250 \mathrm{~m}$ & 104861 & 849 & $74.57 \%$ \\
$250-500 \mathrm{~m}$ & 26321 & 213 & $18.72 \%$ \\
$500-1000 \mathrm{~m}$ & 7365 & 60 & $5.24 \%$ \\
$>1000 \mathrm{~m}$ & 2071 & 17 & $1.47 \%$ \\
\hline
\end{tabular}

Table 2 Area of ice thickness classes.

Regions where the estimate is likely to be unreliable are concentrated in two general regions: inland zones crossing ice-sheds, and the coastal ends of some large glaciers. In both cases, the unreliability is caused by break-down of the basic assumptions of the technique.

Areas in the vicinity of ice-sheds are unreliable because ice motion in these regions has a strong vertical component, defeating the simple analysis of section 2.1.

Areas in the coastal regions of glaciers are almost certainly lubricated at the bed, and the limiting basal shear stress is substantially reduced from the nominal value of $100 \mathrm{kPa}$. Furthermore, the assumption of plastic flow may also be untrue in this area; the ice may be moving as a block sliding over the base. This is shown by examination of satellite images, which show evidence of rapid streaming flow evidenced by the presence of flow-lines (figure 4). The stream-lines can be better seen in this link (Google Maps), which provides access to high resolution copyright images.

\section{DISCUSSION}

The ice thicknesses presented here must only be regarded as estimates, with potential systematic errors of $\pm 50 \%$ due to the unknown actual value of the limiting basal shear stress. However, with this proviso, it is very encouraging that at least $75 \%$ of the ice area provides results that appear to be reasonable, and perhaps another $10 \%$ of the area $(50 \%$ of the $250 \mathrm{~m}-500 \mathrm{~m}$ ) band may well also be reliable. Comparison with ice thicknesses from similar sized but colder Svalbard glaciers (Dowdeswell et al., 1984) suggests that the ice

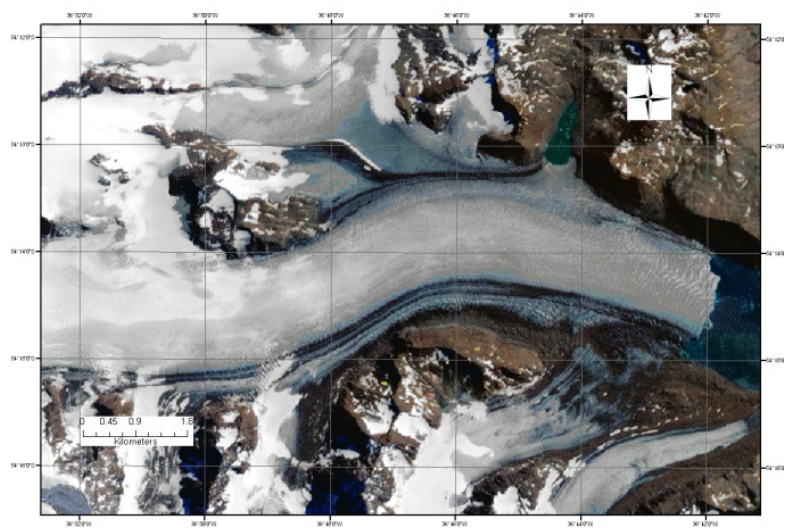

Figure 4 Landsat ETM Image of Neumayer Glacier showing flowlines

thickness estimates of a few hundred metres are of the right magnitude.

The ice thicknesses of Briggs Glacier and Esmark Glacier, coastal glaciers that may be critical to preventing the spread of invasive species (Cook et al., 2009), are shown in Figure 5 and Figure 6. These glaciers, which form barriers to the spread of rats into currently rat-free areas, both show icethicknesses that indicate that the glacier flow conforms to the assumptions of Section 2.2 above. This suggests that previously rapid retreat of these two glaciers may not continue in the future, and that the bed of these glaciers is not lubricated.

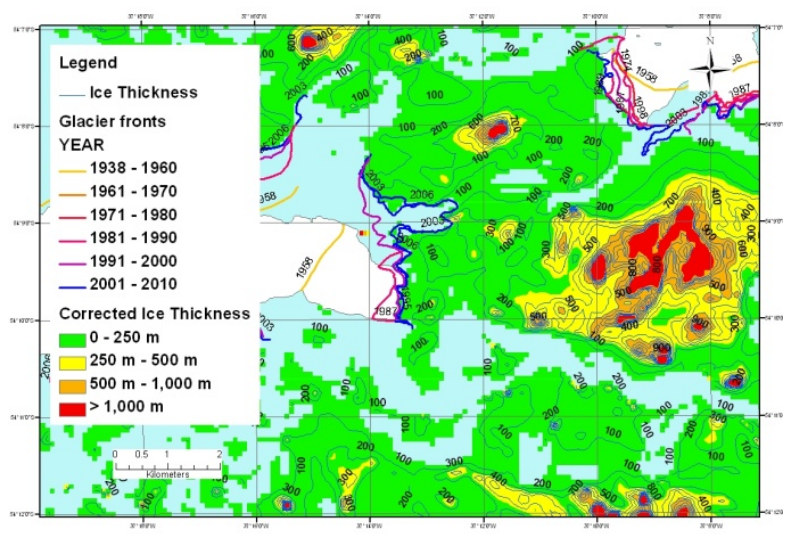

Figure 5 Briggs Glacier showing ice thickness estimates and glacier retreat

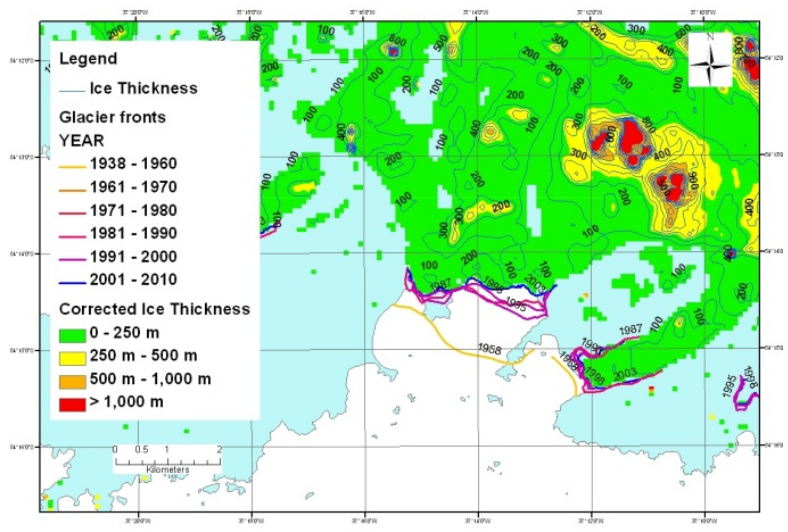

Figure 6 Esmark Glacier showing ice thickness estimates and glacier retreat 
The regions where the estimates are too great fall into two distinct classes. First, regions at or near the ice-sheds, where the horizontal motion of the glacier is small, and the ice velocity vectors have a strong downwards component. In these regions, the ice motion does not correspond to the simple model of Section 2.1, and so the ice thickness estimates are too great. However, in these regions (where ice thickness is expected to be at its greatest), the estimates in the range $250 \mathrm{~m}-500 \mathrm{~m}$ are more likely to be correct.

More interesting are the regions in the coastal extremities of certain large glaciers. As noted above, it is likely that in these regions the increased thickness estimates are due to decoupling of the glacier from the bed, reducing the limiting basal shear stress, and so causing an over-estimate of the ice thickness. This decoupling is likely to be caused by the presence of water at the bed of the glacier. The darker ice shown in Error! Reference source not found. indicates that the apparently high thickness region on Neumayer Glacier corresponds to the ablation zone of the glacier, as well as showing other evidence of bed decoupling in the form of stream-lines.

Of the major glaciers of South Georgia, two on the north coast (Neumayer Glacier (Figure 7) and Ross Glacier (Figure 8)) showing this bed decoupling also show rapid retreat. Neumayer Glacier has retreated by over $4 \mathrm{~km}$ and Ross Glacier by $3 \mathrm{~km}$. Nordenskjöld Glacier (Figure 9Figure 8), in a similar setting, has retreated, but only by $850 \mathrm{~m}$, a much smaller retreat. A fourth, Brøgger Glacier (Figure 10), on the south coast, shows no retreat at present.

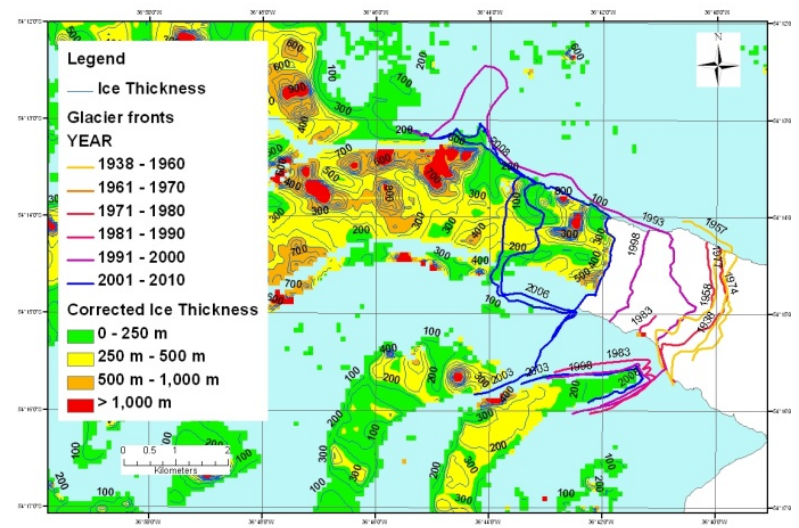

Figure 7 Neumayer Glacier showing ice thickness estimates and glacier retreat

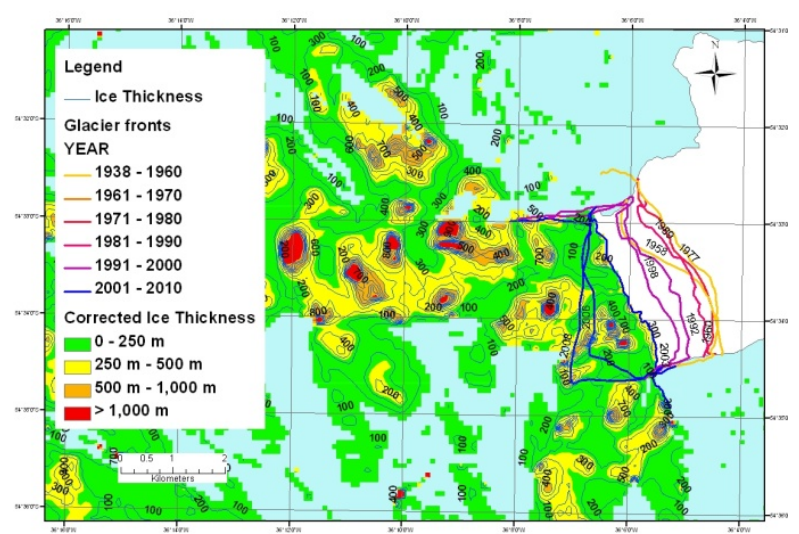

Figure 8 Ross Glacier showing ice thickness and glacier retreat

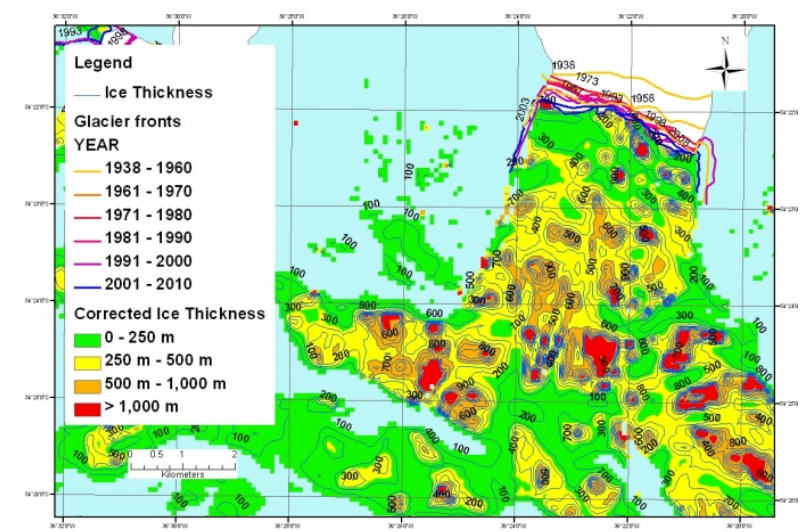

Figure 9 Nordenskjöld Glacier showing ice thickness and glacier retreat

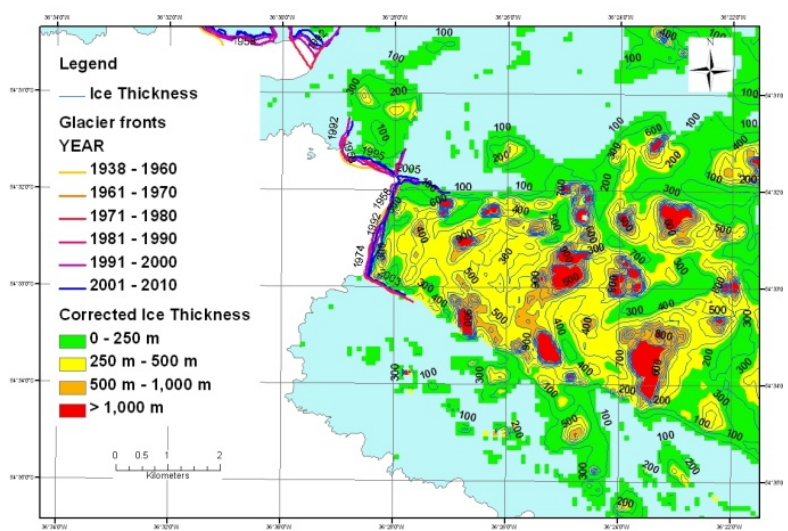

Figure 10 Brøgger Glacier showing ice thickness and glacier retreat

It is noteworthy that the three glaciers showing retreat are all on the north coast of South Georgia, and because of prevailing westerly wind direction, the orographic effect of the mountains forming the central spine of the island will cause a lower accumulation rate than that to the south of the central mountains. Any reduction in the accumulation rate or increase in the elevation of the equilibrium line due to increasing temperatures will cause rapid retreat, especially where the glacier velocity is high. The temperatures at Grytviken, on the north coast of South Georgia, show that summer (January) temperatures have increased significantly since observations began in 1905 , and are nearly two degrees higher than the minimum temperatures observed in the $1930 \mathrm{~s}$ (Figure 11). Winter temperatures show little, if any, change.

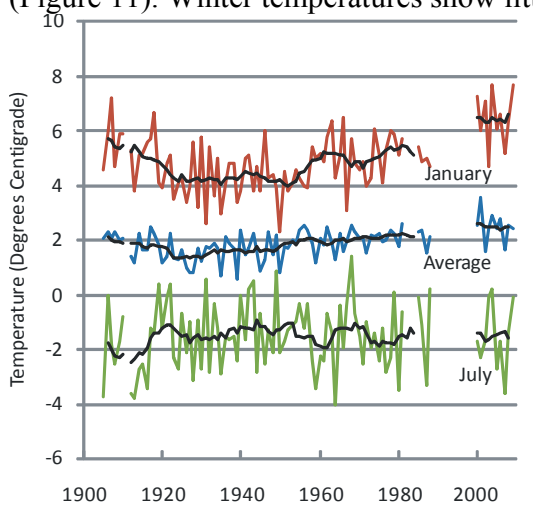

Figure 11 Temperatures recorded at Grytviken. The black lines are 10 year moving averages. 
The anomalous ice thickness values for Brøgger Glacier suggest that the glacier is sliding over its bed. Therefore, it requires a high accumulation rate in the upper part of the glacier to sustain the rapid motion in the lower part of the glacier. We can predict that Brøgger glacier may retreat rapidly if the accumulation rate south of the central mountain ranges decreases, either because of increasing temperatures raising the equilibrium line of the glaciers, or because of reduced precipitation.

\section{CONCLUSIONS}

In the absence of other data, the analysis of this paper shows that surface slope derived from remotely-sensed surface elevation measurements can provide a useful estimator for ice thickness. In addition, the paper shows that useful conclusions can be drawn from regions where it is apparent that the underlying assumptions of the technique break down. In particular, we make the prediction that Nordenskjöld and Brøgger Glaciers will retreat rapidly at some point in the future, as increasing global temperatures reduce the accumulation available to drive these glaciers.

\section{ACKNOWLEDGEMENTS}

The authors wish to express their appreciation for input from their colleagues, especially Mr A H Fleming and Mr D J Herbert of BAS. Mr Tate wishes to express his thanks to Professor I Dowman, his supervisor at University College, London.

\section{REFERENCES}

A. J. Cook, S. Poncet, A. P. R. Cooper, D. J. Herbert, D. Christie (2010), Glacier retreat on South Georgia and implications for the spread of rats, Antarctic Science.

Dowdeswell, J. A., D. J. Drewry, O. LiestøL and O. Orheim (1984). "Radio echo-sounding of Spitsbergen glaciers: problems in the interpretation of layer and bottom returns." Journal of Glaciology 30(104): 16-21.

Drewry, D. J. (1983). Antarctica: Glaciological and Geophysical folio. Cambridge, Scott Polar Research Institute.

Farr, T. G., et al. (2007), The Shuttle Radar Topography Mission, Rev. Geophys., 45, RG2004, doi:10.1029/2005RG000183.

Paterson, W. S. B. (1981). The physics of glaciers. Oxford, Pergamon: $380 \mathrm{pp}$. 